\title{
Girişimciliğin Öteki Yüzü: Başarısız Girişimci Deneyimlerinden Dersler
}

\author{
Vasfi KAHYA ${ }^{1}$
}

Öz

Girişimcilik konusu hem bireyler hem de toplum için çok önemli bir kavramdır. Girişimcilikle ilgili popüler ve akademik çalışmalarda başarı faktörünün üzerinde durulduğu görülmektedir. Ancak istatistikler, ülkemizdeki yeni girişimlerin ciddi oranda başarısızlıkla sonuçlandığını göstermektedir. Dolayısıyla başarı kadar başarısızlık da girişimcilikteki önemli kavramlardan birisidir. Girişimcilikte başarısılık konusu bireysel ve örgütsel düzeyde, objektif ve sübjektif olarak düşünülebilir (Jenkins ve MacKelvie, 2016). Bu çalışmada başarısız olduğunu kendileri ifade eden girişimcilerin videoları içerik analizine tabi tutularak ön plana çıkarılan başarısızlık temaları ortaya çıkarılmıştır. Bu şekilde girişimciliğin ihmal edilen yönlerine ve tersine mantık kullanılarak başarısızlık faktörlerine dikkat çekilmektedir. Girişimcilerin başarısız olması mevcut girişimin sona ermesi anlamına gelmekle birlikte girişimcinin daha sonraki girişimlerinde başarılı olduğunu gösteren çok sayıda örnek mevcuttur. Bu çalışma sonucunda girişimcilerin başarısızlık faktörlerinin girişimcilikte başarı için gerekli olan faktörleri tamamladığ1 görülmektedir. Başarısızlık hikayeleri hem uygulamada hem de akademik düzeyde öğrenmeye katkı yapabilir.

Anabtar Kelimeler: Başarısızlık, Başarısız girişimciler, Başarısız girişim, İflas, Girişimcilik fırsatı

\section{The Other Side of Entrepreneurship; Lessons from Failed Entrepreneur Experiences}

\begin{abstract}
Entrepreneurship is a very important concept for both individuals and society. It is observed that the success factor is emphasized in popular and academic studies related to entrepreneurship. However, statistics show that new initiatives in our country have resulted in serious failure. Therefore, success as well as failure is one of the important concepts in entrepreneurship. The issue of failure in entrepreneurship can be considered on individual and organizational levels, objectively and subjectively (Jenkins,\&MacKelvie, 2016). In this study, videos of entrepreneurs who express themselves that they have failed will be subjected to content analysis and the themes of failure will be revealed. In this way, attention will be drawn to neglected aspects of entrepreneurship and failure factors using reverse logic. While failure of entrepreneurs means the end of existing enterprise, there are many examples where the entrepreneur succeeds in following initiatives. As a result of this study, it is seen that the failure factors of entrepreneurs complement the factors necessary for success in entrepreneurship. Stories of failure can contribute to learning both in practice and at the academic level.
\end{abstract}

Key Words: Failed entrepreneurs, Failed entrepreneurship, Bankruptcy, Entrepreneurship opportunity

Atıf İçin / Please Cite As:

Kahya, V. (2020). Girişimciliğin öteki yüzü: Başarısız girişimci deneyimlerinden dersler. Manas Sosyal Araştırmalar Dergisi, 9(4), 2447-2458.

Geliş Tarihi / Received Date: 02.05.2020

Kabul Tarihi / Accepted Date: 05.08.2020 


\section{Giriş}

Girişimcilik literatüründe en çok vurgulanan kavramlardan birisi başarı kavramıdır. Başarı süreci ve başarı faktörlerini ele alan çalışmalarda; yenilikçilik, firsatları değerlendirme, farklı düşünebilme gibi bireysel ve kurumsal düzeyde birçok faktörden bahsedilmektedir (Aytaç ve İlhan, 2007; Ball, 2017; Bozkurt vd., 2018). Girişimcilik özü itibariyle belirsizlik ve dolayısıyla muhtemel başarısızlık içermektedir. Bu özelliği en eski girişimcilik metinlerinde ifade edilmesine rağmen (Knight, 1921; Schumpeter, 1934) günümüzde unutulmuş görülmektedir (Jenkins ve MacKelvie, 2016). Yapılan bir çok çalışmada girişimcilikte başarı konusu ele alınmış olmasına rağmen, girişimcilik alanında ihmal edilmiş ve karanlıkta kalmış alanlardan birisi de girişimcilikte başarısızlığın anatomisinin ortaya konulmasıdır (McGrath, 1999; DeTienne, 2010; Sarasvathy vd., 2013) ve son dönemde başarısızlı̆ı̆n girişimci üzerindeki etkileri de önem kazanmıştır (Üçbaşaran vd., 2013).

Girişimcilik literatüründe başarı ve başarısızlık kavramları bireysel ve örgütsel düzeyde ele alınmakla birlikte her iki tür başarısızlığın eş anlamlı kabul edilmesi doğru değildir (Jenkins ve MacKelvie, 2016). Analiz düzeyleri farklı olan iki farklı süreçten bahsetmek daha doğru olacaktır (Cardon vd., 2011). Buna kanıt olarak başarısız girişimcilerin girişimlerini bitmelerine rağmen başarısız olarak atfedilen bu girişimciler başka girişimlere devam ederek başarılı olmaları mümkündür (Sarasvathy vd., 2013). Bir başka ifadeyle girişimin başarısız olması, her durumda, girişimcinin başarısız olması demek değildir (Sarasvathy, 2004; Hsu vd., 2017).

Girişimcilik kavramının ve sürecinin daha iyi anlaşılabilmesi için başarı ve başarısızlık bakıș açılarının birleştirilmesi gerekmektedir. Bu bize girişimcilik hakkında daha kapsamlı bir perspektif kazandıracaktır (Üçbaşaran vd., 2013). Başarı ve başarısızlık kavramları çok boyutlu birer kavram olarak ele alınmalıdır. Bu sebeple, başarısızlığı tek bir unsur olarak değil de farklı seviyelerde ve farklı faktörleri değerlendirerek anlaşılması gereken bir süreç olarak almamız gereklidir.

Literatürde girişimcilerin karşılaştığı sorunlar ve çözüm yollarına ilişkin çok sayıda çalışma bulunmaktadır. Ancak yapılan çalışmaların genelde teorik ya da sayısal verilere dayalı nicel çalışmalardan oluştuğu görülmektedir. Buna karşılık nitel yöntemler kullanılarak yapılan çalışmaların daha derinliğine bilgiler içermesi beklenir. Bu anlamda kullanılan başarısız girişimcilerin videoları, daha önce bahsedilmeyen farklı faktörlerden bahsetmekte ve bu anlamda literatürdeki boşlukları doldurmaya yardım etmektedir.

$\mathrm{Bu}$ çalışmada, girişimcilikte başarısızlık olgusuyla başarısız girişimci olgusu farklı anlamlarda kullanılmaktadır. Bu çerçevede internetten tesadüfi örneklemeyle seçilen, Türkiye'de başarısı girişimler üzerine bizzat girişimciler tarafindan hazırlanan videolar içerik analizine tabi tutulmuş ve elde edilen temalar, mevcut girişimcilik literatüründeki başarı faktörleriyle karşılaştırılmıştır. Bu çalışmayla girişimcilik kavramına, başarısızlık perspektifinin de eklenmesiyle daha geniş bir açıdan bakılarak ilgili alana katkı yapılması amaçlanmıştır.

\section{Girişimcilikte Başarısızlık}

Girişimcilikte başarısızlık kavramını, genelde girişimlerin sona ermesi, iflas etme ve işin batması olarak ifade ederiz. Tarihsel olarak bakıldığında girişimin başarısızlığı ile girişimcinin başarısızlğ̆ eş anlamlı olarak kabul edilmiştir (Wennberg vd., 2010). Buna karşın, başarısızlık kavramlarını bireysel analiz düzeyinde ve örgütsel analiz düzeyinde farklı olarak algılayan çalışmalar da mevcuttur (Wennberg vd., 2010; DeTienne vd., 2014). Girişimlerin sona ermesi her zaman başarısızlık olarak algılanmamalıdır. Örneğin, bazı girişimciler yatırımlarının meyvelerini almak için girişimlerini nakde dönüştürebilirler (DeTienne, 2010), bazı girişimciler emekli olabilir veya alternatif istihdam firsatlarını takip etmek için girişimlerini kapatabilirler (Watson ve Everett, 1996; Headd, 2003). Bu şekilde girişimin sona ermesi anlamına gelen (işten/sektörden) çıkışlar genellikle başarısızlıktan ziyade pozitif çıkışlar olarak görülmüsştür (DeTienne vd., 2014). Girişimcilerin iflas vb. gibi finansal sıkıntılar sonucu girişimlerini kaybetmeleri, başarısızlık olarak adlandırılabilir (DeTienne, 2010). Bu sebeple, girişimcinin kurduğu girişimden çıkması başarısız olarak değerlendirilmesini gerektirmeyebilir. Burada önemli olan nokta bireysel ve örgütsel başarısızlığı, içinde bulunulan koşullar ve sonuçlara göre değerlendirmektir.

Başarısız girişimciliği şirket düzeyinde tanımlamak daha kolay olabilir. Kapatılan girişimlerin finansal durumlarının incelenmesi sonucu iflas etmiş ya da zarar etmekte olan şirketler görülebilir ve bu girişimlerin ekonomik getirisi, devam etmeyi gerektirecek düzeyde değildir (Coad, 2014) veya başka bir deyişle, verimlilik düştüğü için girişime daha fazla yatırım yapmak anlamsız olacaktır (Wennberg vd., 2010). Girişimlerin kapanmasının büyük bir kısmı girişim başarısızlı̆ına dayanmaktadır, ancak girişimlerin 
başarısızıklarının da tanımlanması gerekmektedir (Coad, 2014). Bu sebeple, girişimlerin başarısızlığını ölçecek ek kriterler belirlenerek başarısızlığın ekonomik açıdan tanımlanması mümkün olacaktır.

Her ne kadar girişim ve girişimci başarısızlı̆ının farklılaştırılması gerekse de, bağımsız girişimlerde, bir girişimciyi kilit bir kaynak olarak girişimden ayırmak zordur (Üçbaşaran vd., 2013), çünkü girişimciler işletmenin beşeri sermayesidir (Alvarez ve Busenitz, 2001). Girişim başarısızlı̆ı̆ın bireysel ve örgütsel düzeyde birlikte anlamak önem kazanmaktadır.

Girişim başarısızlı̆ı konusunda artan ilgiye rağmen, akademik literatürde ve popüler anlamda çok az ampirik çalışma yapılmaktadır (McGrath, 1999; Zacharakis vd., 1999; Shepherd, 2003). Bu sebeple başarısızlı̆ın ne zaman yapıcı ne zaman yıkıcı etkileri olduğu hususunda farklı görüşler bulunmaktadır (McGrath, 1999). Daha öncede ifade edildiği üzere, yapılan çalışmaların bir çoğu girişim ve girişimci başarısızlı̆ı arasında ayrım yapamamaktadır (Cardon vd., 2011, s. 80). Başarısızlık finansal anlamda bazen çok kesin ölçülerde başarısızlık olarak kabul edilebilir ancak birçok başarısızlığın başarıya yakın gri alanda yer aldığ1 söylenebilir (Rerup, 2006).

Girişim başarısızlığında objektif olarak bakıldığında iflas etmek ve resmi olarak girişimi sona erdirmek durumları kabul edilebilir (Shepherd ve Wiklund, 2006) ve girişimin gelir/gider dengesinin geri dönülemeyecek boyutta olumsuz olması anlaşılır. Girişim artık mevcudiyetine devam edemez ve kapanmak zorunda kalır (Shepherd, 2003, s.318). Girişimciler için iflas kesin başarısızlık sebepleri arasında en başta yer almaktadır (Shepherd vd., 2009; Shepherd ve Haynie, 2011). Seri girişimciler (birden çok girişim yapmış olan girişimciler) ve ilk kez girişimcileri için durum biraz farklıdır; seri girişimciler başarısız bir girişimden sonra yeni girişime başlayabilirler (Üçbaşaran vd., 2010). Yakın zamanlarda, girişimlerin başarısızlığının duygusal etkileri ampirik olarak araştırılmıştır (Byrne ve Shepherd, 2013; Jenkins vd., 2014). Literatürde ayrıca başarısızlık durumunda, girişimcilerin başa çıkması gereken sorunlar üzerinde de durulmuştur (Shepherd ve Haynie, 2011).

Girişimcilerin başarısızlığı konusu, literatürde, daha çok subjektif bir konu olarak da görülmektedir ve başarısızlı̆ karar vermek için girişimin sona ermesi anında girişimin performansına bakılmaktadır (Gaskill vd., 1993; Headd, 2003). Örneğin, Headd (2003) tarafindan yapılan çalışmada girişimcilere, girişimleri sona erdiği zaman başarı durumları sorularak başarısızlıkları analiz edilmiştir. Bu kavramsallaştırma, girişimlerin başarısızlık oranlarını hesaplamada ve tahmin etmede de kullanılmıştır (Headd, 2003; Bates, 2005). Böylece sona eren girişimlerin finansal performans gibi objektif başarısızlık faktörlerinden dolayı $\mathrm{m}$ yoksa başka sebeplerle mi sona erdiği anlaşılmaya çalışlmıştır (Wennberg vd., 2010). Performansı düşük olsa da hedeflerine ulaştığını düşünen girişimciler kendi iradeleriyle girişime son verebilirler. Bu durumu DéTienne vd. (2014) girişimcilerin "gönüllü bırakma" stratejileri olarak ifade etmektedir ve bu durumda girişimin belirlenen hedeflere ulaştığını düşünen girişimciler daha fazla faaliyet göstermekte bir yarar görmeyebilirler. Bu şekilde verilen kararla girişimlerin sona ermesi, başarısızlığın öznel bir görünümü olarak, "pozitif” veya “negatif” olarak görülebilir (Bates, 2005).

Objektif olarak bir girişimcinin bireysel düzeyde başarısızlık kavramsallaştırmasında, girişimcilerin başlangıçta kendileri için belirledikleri performans standartlarına ulaşamadığında kendini başarısız bulmaları sonucunda girişimi sona erdirmesi kriteri kullanılabilir. Bu yaklaşım, Gimeno vd.'nin (1997) ortaya attı̆̆ eşik performans teorisinden esinlenmiştir. Bu durumda aynı performans seviyesinde yer alan bir girişimci kendini başarısız olarak görürken başka bir girişimci başarılı olduğunu düşünebilir. Burada farkı oluşturan nokta, beklentilerin farklllığ yanında, girişimcinin beşeri sermayesini başka bir girişimde kullanıp kullanmamasıdır (McGrath, 1999). Burada beşeri sermayesi yüksek olan girişimcilerin başarısızlık eşiği daha yüksek olacaktır (Gimeno vd., 1997). McGrath (1999) girişimcinin sahip olduğu kaynakların alternatif kullanımlarına dayanarak, başarısızlığ "hedeflerinin altında kalan girişim" olarak tanımlamıştır (s.14). Üçbaşaran vd. (2013, s. 26) de benzer bir şekilde, girişim başarısızlı̆̆ını, bir girişimin ekonomik olarak sürdürülebilir seviyeyi ve eşik değerini aşması şeklinde ele almışlardır.

Önceden belirlenen kriterlerin karşılanamaması durumunda, ilk defa girişimcilik yapan ya da daha önce tecrübesi olan girişimcilerde farklı sonuçlara ulaşılmıştır (Politis ve Gabrielsson, 2009; Üçbaşaran vd., 2010). Örneğin, Üçbaşaranvd.'nin (2010) yaptıkları çalışmada, katılımcılara daha önce girişimleri olup olmadığı ve bu girişimleri kapatıp kapatmadıklarını sorarak beklentilerin farklılı̆ıına dikkat çekmişlerdir. Daha önce girişimde bulunmuş girişimciler, başarısız oldukları zamanlarda bile, ilk defa girişim kuranlara kıyasla iyimserliklerini koruyarak başarısız olduğunu düşünmemişlerdir. 
Sübjektif olarak girişimcilerin başarısızlı̆̆ üzerine son zamanlarda birçok çalışma yapılmıştır. Yapılan bazı örnek olaylar sonucunda, girişimci başarısızlığı, başarısızlığın etkileri üzerinden kavramsallaştırılmıştır (Singh vd., 2007; Cope, 2011; Jenkins vd., 2014). Bununla birlikte başarısızlığın girişimci üzerindeki etkileri farklı boyut ve yönlerde olabilmektedir. Her ne kadar başarısızlı̆̆ın, başarısız olan girişimciye dahi ders verici ve öğretici olduğu iddia edilse de (McGrath, 1999) başarısızlığın duygusal ve travmatik etkileri kaçınılmazdır (Shepherd, 2003; Cope, 2011) ve bu da öğrenmeyi engeller. Öğrenme başarılı olsa bile, aynı girişimci başarısızlıktan öğrendiklerini yeni girişimine hemen taşıyamayacaktır (Shepherd, 2003; Üçbaşaran vd., 2010). Başarısızlı̆ı̆n (finansal, sosyal ve psikolojik) maliyetiyle hatalardan ders alabilme arasında denge kurulmalıdır, eğer girişimci maliyetleri ve negatif etkileri çok yüksek bulursa girişimcilikten vaz geçebilir. Bu da hem girişimci hem de toplum adına bir kayıp olacaktır.

Kişisel başarısızlık, hem girişimcinin kendi algılaması hem de başarısızlığın etkileri üzerinden katılımcılara sorularak da araştırılmıştır. Örneğin, Singh vd. (2007) girişimcilerin girişimin sona ermesinden sonra karşılaştı̆̆ duygusal zorlukları incelemiştir. Cope (2011) tarafından yapılan çalışmada, girişimcilerin girişimleri sona erdikten sonra, hayatlarının nasıl etkilendiği ve başarısız tecrübelerinden ders almaları üzerinde durulmuştur. Bu konuda yeterince ampirik çalışma yapılmamıştır (Frankish vd., 2013). Bu çalışmalar daha çok başarısızlıkla ve etkileriyle mücadele konularına eğilmişsir. Bu çalışmalar genelde başarısızlığın bireysel etkilerinden hareketle başarısızlığı ele almıştır. Jenkins vd. (2014) de, başarısızlık sonrası ortaya çıkan duygusal çöküntü ve etkilerini analiz ederek başarısızlı̆̆ı anlamaya çalışmışlardır.

Yönetim literatüründe olduğu gibi, girişimcilik literatüründe de girişimcilerin başarısız deneyimlerinden ve hatalarından öğrenmesi konusu işlenen bir konudur (Cannon ve Edmonson 2005; Madsen ve Desai, 2010). Bu konuda yapılan çalışmalar, girişimcilerin başarısızlık sonucunda ortaya çıan tecrübeleri üzerinde durmuştur (McGrath, 1999; Shepherd, 2003; Cope, 2011; Simmons vd., 2013; Singh vd., 2015). Başkalarının hatalarından öğrenme konusunda, "kötü iyiden güçlüdür" (Baumeister vd., 2001) anlayışının etkisiyle, başarısızlıklar daha ögretici olmaktadır. Psikolojik olarak, kötü tecrübeler insanları iyi tecrübelere göre daha çok etkilemektedir (Bledow vd., 2017). Girişimcilikte başarısızlığın tanımlanması başarısızlı̆̆a verilen anlamla yakından ilişkilidir. İflas sonucu başarısızlık durumu artık görülebilir bir düzeydedir ve hem girişimcinin hem de toplumun girişimcilerle ilgili algılamasını negatif etkilemektedir (Cardon vd., 2011) ve bu durum girişimde bulunma niyetinde olan girişimci adaylarını olumsuz olarak etkileyebilir (Simmons vd., 2013). Başarısızlıkla mücadele etme ve alg1 yönetimi stratejileri başarısızlık durumunda devreye girebilmektedir (Shepherd ve Haynie, 2011).

\section{Türkiye’de Girişimcilikte Başarısızlık Literatürü}

Girişimcilik hem bireysel olarak hem de toplumsal olarak önemli bir konu olmasına rağmen, yeni kurulan girişimlerin önemli oranda başarısızlıkla sonuçlandığı bilinmektedir. Örneğin, 2017 yılı içerisinde Türkiye'de kurulan 73.783 şirketin 14.701 adedi, bir başka ifadeyle yaklaşı \%20'si başarısız olmuş ve kapanmıştır (tobb.gov.tr). Burada kapanan şirketlerin hangi nedenlerle ve amaçlarla kapatıldıkları, girişimcinin ilk girişimi mi olduğu gibi hususların incelenmesi gerekmektedir. İlk defa girişimde bulunan girişimcilerin başarısızlık ihtimalinin, daha önce girişimde bulunmuş ve daha tecrübeli girişimcilere oranla daha yüksek olması beklenmektedir (Jenkins ve McKelvie, 2016, s. 422).

Girişimciliğin ekonomik gelişme, istihdam yaratma ve yenilikçilikte çok önemli bir rolü bulunmaktadır (Carree ve Thurik, 2010; Lee vd., 2011). Bununla birlikte yeni girişimlerin önemli bir kısmı her zaman başarısız olabilmektedir (Headd, 2003; Wiklund vd., 2010). Girişim başarısızlı̆̆ı, başarısız olan girişime ait birçok bilgi ve kaynaklar açığa çıktığı için ekonomi ve toplum için yararlıdır (Knott ve Posen, 2005; Hoetker ve Agarwal, 2007) ve bu durum, "açığa çıan bilgi ve kaynakların yeni girişimlerde kullanılabilmesi” anlamına gelmektedir (Delacroix ve Carroll, 1983, s. 278). Ayrıca, iş başarısızlığı, vekâleten öğrenme yoluyla hayatta kalan işletmelerin maliyetlerinin düşmesine neden olabilir (Madsen ve Desai, 2010).

Girişimcilik literatürünün önemli bir kısmı gelişmiş ülkelerde ortaya konulmuştur ve ortaya konulan olgular, gelişmiş ekonomilerde daha geçerli olarak görülebilir (Bruton vd., 2008; Karimi vd., 2017). Gelişmekte olan ülkelerin farklı sosyal, kültürel ve ekonomik şartlarının olması bu durumun temel sebebidir. Ülkelerin farklı alanlardaki kaynaklarının farklı gelişmişlik seviyelerinde olması da, üzerinde durulması gereken önemli faktörler arasındadır (Welter ve Smallbone, 2006). Finansal kaynakların yanında insan kaynakları ve özellikle insan sermayesinin farklıllğı girişimcilik alanındaki anlayış farklılığını ortaya çıarmaktadır. Tüm bu çevresel faktörler başarı ve başarısızlık durumlarını ve algılamalarını etkilemektedir. 
Ülkemizde girişimcilik alanında yapılan çok sayıda çalışma mevcuttur (Pehlivanoğlu ve Kayan, 2019). $\mathrm{Bu}$ çalışmalar genelde, girişimciliğin ülke ve ekonomi açısından ne kadar önemli olduğu, girişimci özellikleri, girişimciliğin desteklendiği ve insanımızın girişimciliğe birçok açıdan uygun olduğu gibi sonuçlara ulaşmaktadır (Arıkan, 2002; Müftüoğlu, 2003; Güney, 2004; Bozkurt vd., 2012; Derindă̆, 2018). Ülkemizde girişimcilikle ilgili çalışmaların odağında girişimcilik eğilimi bulunmakta ve dolayısıyla daha çok bireysel bakış açısı hâkimdir (Eser ve Yıldız, 2015). Girişimcilikle ilgili çalışmalar, girişimlerin çoğunlukla başarıya ulaştığı varsayımına dayanmakta ya da başarısız girişimler dikkate alınmamaktadır (Keskin, 2018). Ülkemizdeki girişimcilikte başanı ve başarı öyküleri üzerine çok sayıda çalışma, kitap, video gibi dokümanlar olmasına rağmen başarısızlık literatürü yeterince gelişmemiştir. $\mathrm{Bu}$ durumun ortaya çıkmasında, başarısızlıktan hoşlanılmaması sebebiyle bu tür yayınların talep görmemesi kadar başarısız girişimcilerin deneyimlerini aktarmak istememesi de etkili olabilir.

Girişimcilikte başarısızlık üzerine yapılan çalışmaların bir kısmı cinsiyet faktörünü ön plana çıkarmaktadır (Keskin, 2017; Lezki ve Cengiz, 2019). Kadınların toplumda bulundukları dezavantajlı konum nedeniyle girişimlerini kurmak ve devam ettirmek için yaşadıkları zorluklardan bahsedilmektedir. Finansman sağlamak, kredi bulabilmek ve güven sağlamak başta olmak üzere birçok problem kadınların girişimlerini sona erdirmesine sebep olmaktadır. Kadınların bir kısmı finansman sorununu aşmak için kredi kartlarını kullanmaktadır (Arıkan, 2016). Bu çalışmada cinsiyet faktöründen bağımsız olarak yaşanan başarısızlıkların araştırılması planlanmıştır.

Literatürde daha çok başarılı girişimcilerden bahsedilmesine rağmen, başarısız girişimciler ve başarısızlı̆̆a yol açan faktörler üzerinde yeterince durulmamıştır. Bu çalışmada incelenen girişimcilerin yaşadıkları başarısızlığın nedenlerinin, girişimcilik başarısı konusundaki teorik bilgilere katkı vermek amacıyla, analiz edilmesi ve bu şekilde ülkemizdeki girişimcilik çalışmalarına katkı yapılması amaçlanmıştır. Girişimcilerin başarısızlık faktörlerinin analiz edilerek teorik bilgilerle karşılaştırılmasının, gelecekteki girişimci faaliyetlerin başarısını artıracağı düşünülmektedir.

\section{Yöntem}

$\mathrm{Bu}$ araştırmada, girişimcilik başarısızlığı deneyimine sahip olan ve bunun hakkında bilgi veren girişimcilerin kendilerini anlattıkları 15 adet video, içerik analizine tabi tutulmuştur. Seçilen videolar, internette Türkçe olarak "başarısız girişimcilik" ve "başarısız girişimciler" anahtar kelimeleriyle yapılan, arama motoru ve video izleme sitelerinin sonuçlarından tesadüfi örnekleme ile seçilen videolardan oluşmaktadır. Yine elde edilen bu videolar konuyla ilgili çıkan sonuçların 2020 Şubat ayı için tamamına yakınını kapsamaktadır. Videolar dikkatle izlenerek, girişimcilikte başarısızlık sebepleri taranmış ve bununla ilgili notlar alınmıştır. Aynı videolar daha sonra, konusunda uzman ve tecrübeli başka bir akademisyen tarafindan kontrol amaçlı olarak tekrar izlenmiş ve bulunan temalar karşılaştırılmıştır. Bunun sonucunda, girişimcilikte başarısızlık konusunda ön plana çıkan temaların ışığında bulgulara ulaşılmışır.

Öncelikle analiz edilen videoların başlığında başarısızlık gibi negatif bir imgeleme olduğu için izlenme sayılarının başarı hikâyelerinden daha az olması beklenebilir. Yeni iş kurmak isteyen girişimci adaylarının ve yeni girişimcilerin en başta başarısızlıkla ilgili görüşleri dikkate almamaları normal karşılanabilir. Ancak girişimcilerin ve girişimci adaylarının hata yapmasını önleyecek ve başarılı olmalarını kolaylaştırabilecek olan videoları aslında ücretsiz bir danışmanlık hizmeti olarak kabul etmek gerekir.

\section{Bulgular}

Videolardaki verilerin ayrıntılı bir şekilde analiz edilmesi sonucunda ortaya çıkan bulgular aşağıda sunulmuştur ve ortaya çıkan temalar ve bunlarla ilgili katıllımcıların ifadeleri ekteki tabloda sunulmaktadır:

\section{Çevre/Aile Desteği}

Girişimcilerin başarı faktörleri arasında, genelde çevrenin ve özellikle ailenin destekleyici olması gerektiği ifade edilmektedir (Lumpkin vd., 2011; Edelman vd., 2016). Girişimcilerin başarısılzlık videolarında, çevre/aile desteği teması altında dikkat çeken ifadeler arasında, çevre tarafindan eleştiri yapılması ve dalga geçilmesi ve bunların oluşturduğu toplumsal baskı bulunmaktadır. Bununla birlikte eleştirinin kendini geliştirmeye yardımcı olacağının farkında olan girişimciler de olabilir:

"Elestirilmek şok kerymetli bir sey” (V2).

"Bașarısı girișimcilerde genel olarak çevresi șälle dalga geçiyor: x ve yeni projesi”"(V3). 


\section{Eleman/İstihdam}

Eleman/İstihdam teması, girişimlerin başarılı olabilmesi için nitelikli insan kaynağına sahip olması gerektiğini ifade etmektedir. İşi yapabilecek, nitelikli kilit elemanların bulunmasında yaşanan zorluklar (örneğin yazılımc1), uygun ekibin oluşturulamaması ve oluşturulsa bile iş bölümünün ve görev tanımlarının doğru yapılamaması, teknolojik sorunların uzman bulunamadığından çözülememesi, ekip yönetimiyle ilgili sorunlar bu tema altında incelenmiştir. Girişimlerin başarısında yetkin ve nitelikli insan kaynaklarının çok önemli olduğu literatürde vurgulanmaktadır (Üçbaşaran vd., 2008; Martin vd., 2013).

"Mevcut varlklari; insan, imkân, teknik, gibi şeyleri baștan doğru tanyzn kessfedin"(V3).

"Yeterli donanmoma insan, çalısan bulunamuyor" (V3).

\section{Finansman}

Girişimcilik literatüründe sıklıkla başarı şartları arasında başta gösterilen finansman konusu (Brophy ve Shulman, 1992; Bettignies ve Brander, 2007), başarısızlık sebebi olarak da ifade edilmiştir. Finansman temasının altında nakit sıkıntısı, sermaye bulmanın zorluğu ve bu bağlamda melek yatırımcıların önemi vurgulanmaktadır. Girişimlerdeki başarısızlıkla ilgili olarak, başarısızlık girişimciler örneğinde, sadece 4 girişimci tarafından ifade edildiğine baktı̆̆ımızda, finansmanın çok önemli bir problem olarak görülmediği ya da başarısız olmalarında ikincil öneme sahip olduğu dikkat çekmektedir.

"Herkes çözüme para veriyor (bir soruna iyi bir çözüm öneriyorsanı herkes tarafindan fonlanmak mümkün)"

(V13).

"Melek yaturmo olayı öyle kolay değil. Önce işi ortaya koymak gerek" (V2).

"Türkiye'de melek yaturmo zihniyeti yok" (V14).

\section{Ortaklar Arası Anlaşmazlık}

$\mathrm{Bu}$ tema altında; ortaklığın sona ermesine yol açan anlaşmazlıklar, konulan kuralların ve yapılan işlemlerin resmiyete dökülmemesinden kaynaklanan anlaşmazlıklar, genel olarak güven sorunu, beșeri faktörler üzerinde durulmuştur. Başarısız olan girişimlerde ortaklıkla ilgili sorunlar literatürde işlenen konulardan birisidir. Özellikle güven sorunu girişimlerin başarısını doğrudan etkilemektedir (Welter ve Smallbone, 2006; Welter, 2012).

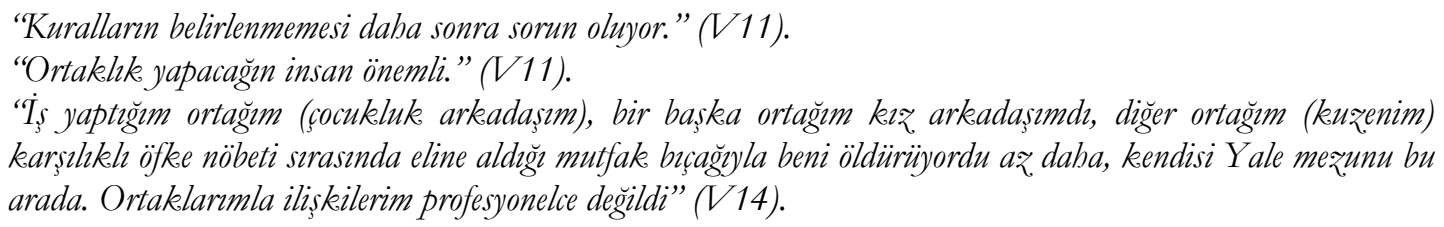

\section{Üretim/Teknolojik/ Fikirsel Adaptasyon}

Literatürde görece az işlenen konulardan birisi olan farklı adaptasyon türlerinin girişimcilik başarısına etkisi temalar arasında yer almaktadır. Yapılan işin görece zor olması, ustalık, teknolojik altyapı gerektirmesi, zaman yönetimi gibi alt faktörlerde yaşanan sıkıntılar başarısızlı̆̆a yol açmaktadır. Girişimlerin başarısında etkili olduğu düşünülen bu temaya ilişkin alt faktörlerden yola çıkıldığında, özellikle teknoloji kabul modelleri konusu ciddi olarak araştırılan konulardan bir tanesidir ancak literatürde girişimcilikle yeterince bağ kurulamadığı dikkat çekmektedir (Pathak vd., 2013; Link, 2017).

"Yavas davrandim, işi iyi yönetemedim, mükemmeliyetçi davrandim, gereksiz. zaman harcadim etkinliklerde ve yaturimo arayısında oldum” (V2).

"Edison ampül için patent başvurusu yaptığında ayn gün iki kişi daha başvurmuş. Yani hiçbir fikir benz̧ersiz. değil" (V7).

"Zamanm gerekleri ve gerçeklerine göre girişim yapmak gerekir (V5).

"En önemli sorun sitenin mobil versiyonun olmamasi (yetersiz. teknoloji)" (V13).

\section{Ego-Rakibini Küçümseme-Ürüne Aşırı Güven}

Girişimcilik literatüründe davranışsal yaklaşımlarda, girişimcilik başarısını etkileyen ve özellikle kişilikle ilgili olan faktörler (özgüven, sabır, kararlılık vb.) sıklıkla vurgulanmaktadır (Macko ve Tyszka, 2009; vonWeizsäcker, 2014). Bu tema altında, ön plana çıkan egoist davranmak ve rakipleri küçümsemek alt faktörleri dikkat çekmektedir. Özgüven konusu vurgulanan kavramlardan birisidir.

"Bir işi başarma isteği, akılcu düsünmeyi bitiriyor; hors ve ego büküm verme kabiliyetinin önüne geçiyor.” (V4). 
"Girişimcinin özgüveninin olmast gerekiyor, hem başar konusunda, hem de başarsı̨̨llk. konusunda” (V10).

"Ürüne aşı olmak problem" (VT).

\section{Piyasa/Kanunlar, Çevre, Rakip Analizi (PEST)}

Girişimlerin başarısız olmasına sebep olan faktörler arasında çevresel faktörler önemli bir yer tutmaktadır. PEST analizine benzer şekilde bu tema altında topladığımız faktörler arasında fizibilite yapılmaması, yasal mevzuatın ihmal edilmesi, tecrübesizlik ve acele etmekten kaynaklanan sorunlar, ekonomik ve coğrafi konuma ilişkin sorunlar ve siyasi konjonktür sayılmaktadır. Çevresel faktörlerin girişimcilik üzerindeki etkileri daha çok iktisadi ve sosyal alanlardaki literatürde yer almaktadır (Gilbert vd., 2004).

"Para, biz̨im Batımızda olan ülkelerde ve onlarn ülkemize bakışı malum. 15 Temmuz olayları yatırmı kesti" (V8).

Paypal gibi ödeme sistemlerinin devlet tarafindan kapatılmast ile yerel girişimlerin yabanclara açılmasmm önü kapatılmıs oldu (V6).

"Türkiye ekonomisinin de kötïye gitmesi bir̨i olumsuz, etkiledi" (V14).

Temalara ve alt faktörlere ilişkin tablo ise aşağıdaki gibidir;

Tablo 1. Temalar ve Alt Faktörler

\begin{tabular}{|c|c|c|c|}
\hline Tema & Frekans & Alt Faktör & Katılımcı Kodu \\
\hline \multirow{3}{*}{ Çevre/Aile Desteği } & \multirow{3}{*}{$3 / 14$} & $\begin{array}{l}\text { Çevre tarafindan eleştiri. } \\
\text { Aile tarafindan destek görmeme. }\end{array}$ & 1 \\
\hline & & Başarısız girişimcilerle alay edilmesi & 3 \\
\hline & & Kapatt1 demesinler (toplum bask1s1) & 10 \\
\hline \multirow{7}{*}{ Eleman/İstihdam } & \multirow{7}{*}{$5 / 15$} & Yazılımcı bulma zorluğu & 2 \\
\hline & & Ekip kurma zorluğu & 3 \\
\hline & & $\begin{array}{l}\text { Yeterli donanımda insan, çalışan bulamamak } \\
\text { Ekip kurmada doğru görev tanımı yapılması }\end{array}$ & \\
\hline & & Cep uygulamas1 yapamama sorunu (teknoloji sorunu) & 5 \\
\hline & & İyi insanlarla çalışmak (Ekip) & 7 \\
\hline & & Doğru ekip & 11 \\
\hline & & Yetersiz yazılım bilgisi & \\
\hline \multirow{4}{*}{ Finansman } & \multirow{4}{*}{$4 / 14$} & $\begin{array}{l}\text { Nakit s1kıntıs1 } \\
\text { Melek yatırımc1 bulamama }\end{array}$ & 2 \\
\hline & & Finansman s1k1ntıs1 & 8 \\
\hline & & Büyümek için sermaye ihtiyac1 & 12 \\
\hline & & Sermaye için çözüm üretmek & 13 \\
\hline \multirow{4}{*}{$\begin{array}{l}\text { Ortaklar Arası } \\
\text { Anlaşmazlık }\end{array}$} & \multirow{4}{*}{$4 / 14$} & Ortağın ayrilmas1 & 2 \\
\hline & & $\begin{array}{l}\text { Ortak kazığ1 (Güven) } \\
\text { Ortaklar aras1 yazıșma eksikliŭi (Resmivet) }\end{array}$ & 8 \\
\hline & & $\begin{array}{l}\text { Akraba kayırmacilığ (ortaklığın bitme sebebi) } \\
\text { Güven sorununun olmas1 } \\
\text { Kuralların baştan belirlenmemesi } \\
\text { Ortaklık yapılacak insan seçimi }\end{array}$ & 11 \\
\hline & & $\begin{array}{l}\text { Ortak sorunu } \\
\text { Güvensizlik sorunu }\end{array}$ & 14 \\
\hline \multirow{3}{*}{$\begin{array}{l}\text { Üretim/Teknolojik/ } \\
\text { Fikirsel Adaptasyon }\end{array}$} & \multirow{3}{*}{$3 / 14$} & Mantı üretmenin zorluğu & 1 \\
\hline & & $\begin{array}{l}\text { Geç uyanma (iş düzgün yapmayan kişiyi geç keşfetme, zaman kaybetme } \\
\text { Yavaş davranma, plansızlık }\end{array}$ & 2 \\
\hline & & En önemli sorun mobil versiyonun olmaması (yetersiz teknoloji) & 13 \\
\hline \multirow{5}{*}{$\begin{array}{l}\text { Ego-Rakibini } \\
\text { Küçümseme-Ürüne } \\
\text { aşırı güven }\end{array}$} & \multirow{5}{*}{$5 / 14$} & Egolu davranmak, rakibi küçümsemek & 3 \\
\hline & & Hirs ve ego & 4 \\
\hline & & Ürüne aş1k olmak problem (duygusal bağllilk) & 7 \\
\hline & & Özgüven & 10 \\
\hline & & Ego sorunu & 13 \\
\hline \multirow{4}{*}{$\begin{array}{l}\text { Piyasa/Kanunlar, } \\
\text { Çevre, Rakip Analizi } \\
\text { (PEST) }\end{array}$} & \multirow{4}{*}{$4 / 14$} & $\begin{array}{l}\text { İşe girerken yeterince araştırma yapmamak } \\
\text { Yasal prosedürlerin göz ardı edilmesi } \\
\text { Ortağın yabancı olması, Türkiye'de işlerin nasıl yürüdüğünü bilmemesi }\end{array}$ & 4 \\
\hline & & Tecrübesizlik & 5 \\
\hline & & $\begin{array}{l}\text { Coğrafi konum } \\
\text { Devlet politikaları }\end{array}$ & 6 \\
\hline & & $\begin{array}{l}\text { Coğrafi konum ve Batının bize bakışı } \\
\text { Siyasi ortam }\end{array}$ & 8 \\
\hline
\end{tabular}




\section{Tartışma, Sonuç ve Öneriler}

Belirsizliğin olduğu yerde, başarı kadar başarısızlı̆̆ın olması da normaldir. Belirsizliklerin hâkim olduğu girişimcilik sürecini sadece başarı odaklı olarak düşünmemek gereklidir. Girişimler başarılı olduğunda da başarısız olduğunda da öğretici olabilir. Başarı hikâyeleri daha ön plana çıkarıldığı için daha öğretici olarak görünse de başarısızlığın verdiği dersler daha kalıcı olacaktır. Bununla birlikte, başarısızlıkta birçok psikolojik, sosyal ve ekonomik etkiden bahsedilmektedir.

Örnek olaylarda da görüldüğü üzere, girişimcilerimiz piyasa gereği ve girişimci kültürü olarak başarısılığı kabul etseler bile toplum normları gereği, başarısızlıklardan ders alma ve gelecekteki girişimlerde bu bilgilerin kullanılması tercih edilmemektedir. Çevre/aile desteği başlığında "kapattı demesinler ve alay edilme korkusu" geçmişte yaşanan başarısız tecrübelerin gün yüzüne çıkmasında engel teşkil ettiğini göstermektedir. Ayrıca en önemli kanıtlardan birisi de başarı hikâyeleri üzerine hazırlanmış videolar daha çok ilgi görürken, başarısızlık hikâyesi içeren videolanın izlenme oranları oldukça düşüktür. Bununla birlikte videoları izleyenlerin anlatılan başarısızlık hikâyelerinden çok şey öğrendiği video altına yapılan yorumlarda dikkat çekmektedir. Bu noktada, videoların alındaki yorumların analiz edilmesi de ilginç olabilir. İzleyiciler genelde başarısızlığını anlatan girişimci ile kendilerini özdeşleştirmektedirler. Bu da öğrenmeyi hızlandırmaktadır. Birçok izleyici, başarısızlıklardan ders almanın farkında olarak videoları ilham verici olarak bulmaktadırlar. Örneğin "tek başarım başarısızlığımı kabul etmek oldu ama geç oldu" yorumu ülkemizde, başarısızlıktan ders almanın kültürel anlamdaki zorluğunu vurgulamaktadır. Bir başka ilginç izleyici yorumu ise şöyledir: "Kaybedenlerin öyle güzel tecrübeleri olur ki bunu sadece kaybedenler anlar. Muhtemelen ileride çok daha dönülmez hatalar yapmamayı tecrübe ediyor insan. Yılmadan yıkılmadan devam ediyoruz". Yapılan yorumlar genelde başarısızlık hikâyelerini mükemmel bir öğrenim süreci olarak nitelendirmektedir. Yorumlardan ortaya çıkan tavsiyelerden biri, "iş ilişskisi başka duygusal ilişki başka, profesyonel ortaklarla ya da güçlüysen ortaksız iş yapacaksın" şeklindedir. Bu da iş yaşamında güven probleminin yaşandığına işarettir. İlginç olan yorumlardan birisi, başarısızlıktan ders almanın değerini bilen girişimci adaylarının olduğunu göstermektedir: "Girişimci karabatak gibidir, karabataklar da dibe daldığ1 kadar hayatta kalır. Vazgeçme devam et".

Yapılan bu çalışma önceki çalışmalar ile karşılaştırıldığında Türkiye literatürü açısından finansal sorunlar, yeterlilik sorunları, pazarlama sorunları, engelleme gibi ana başlıkların daha önce de ön plana çıktığ1 görülmektedir (Soysal, 2010; Keskin, 2018). "Çevre tarafindan eleştiri”, aileden destek görmeme" gibi geçmiş çalışmalarda da görülen engelleme sorunları hala devam etmektedir. "Ekip kurma zorluğu" gibi sorunlar ise yeterlilik sorunu ile örtüşmektedir (Üçbaşaran vd., 2008). Bu çalışmada yine literatürle örtüssen finansman sorunları ifadeleri bulunmaktadır.

Uluslararası literatür açısından bakıldığında ise girişimcilerin ego ile ilişkili olan kavramlardan özgüven, sabır ve kararlılık ile ilgili söyledikleri ifadelerin uluslararası literatürle uyuştuğu görülmektedir (Macko ve Tyszka, 2009; vonWeizsäcker, 2014). Güven sorunu ile ilgili ifadelerde ise yine aynı şekilde benzerlikler olduğu görülmektedir (Welter ve Smallbone, 2006; Welter, 2012). Çevre ve aile desteği konuları uluslararası literatürde de sıklıkla dikkat çekmiş bu çalışmaya benzer sonuçlar ifade edilmiştir (Lumpkin vd., 2011; Edelman vd., 2016).

Videolardaki girişimciler başarısızlıklarının değerini bilmekte ve aslında çok pahalı bir eğitim aldıklarını düşünmektedirler. Başarısızlığın başarıya dönüşeceğini ifade etmektedirler. Girişimci başarısızlıklarının hem uygulamada girişimci adaylarına hem de mevcut girişimcilere katabileceği birçok katkı bulunmaktadır. Bu anlayısıın girişimcilik eğitimlerinde de verilmesi gerekir. Buna benzer şekilde girişimcilik başarısı üzerine yazılmış çok sayıda biyografi ve oto biyografi olmasına rağmen başarısız girişimciler üzerine çok az sayıda çalışma mevcuttur. Steve Jobs örneğinde olduğu gibi, daha sonra başarılı olmuş (seri) girişimcilerin önceki başarısızlıkları ilgi çekmektedir. Ülkemizdeki başarılı birçok girişimcinin de başarılı olmadan önce başarısız deneyimlerinin olması muhtemeldir, ancak bunlar hem akademik anlamda hem de popüler olarak dile getirilmemektedir.

Bu sebeplerle, ülkemizde girişimciliğin uygulamada ve akademik düzeyde geliştirilmesi için, ihmal edilmiş olan, girişimcilerin başarısızlık sebeplerinin girişimci deneyimlerinden yola çıkarak araştrılması ve bu örneklerden hareketle gerçekçi öneriler geliştirilmesi gerekmektedir. Akademik düzeyde girişim ve girişimci başarısızlığının daha derinliğine olarak araştırılması ve mevcut girişimcilik literatürüne katk1 yapması önerilmektedir. Böylece, hem girişimci adayları hem de mevcut girişimciler, hatalardan ders alabilecekleri kaynaklara ulaşarak daha başarılı olacaklardır. Başarısız olduğunu kabul edebilen ve kendilerini sorgulayan kişilerin girişimcilikle ilgili tecrübeleri çok değerli bir bilgi kaynağı olarak görülmelidir. 
Bu çalışmanın daha kapsamlı olabilmesi açısından ilerde yapılacak çalışmalar için örnek sayısının arttırılması önerilebilir. Bununla birlikte başarısız girişimcileri sektör temelli ele alınması yaşanan sorunların daha kapsamlı bir çözüm önerisi sunabilmesi açısından önem taşıyabilir.

\section{Etik Beyan}

"Girişimcilig̈̈n Öteki Yü̈ü: Başarısı Girişimci Deneyimlerinden Dersler" başlıklı çalışmanın yazım sürecinde bilimsel kurallara, etik ve alıntı kurallarına uyulmuş; toplanan veriler üzerinde herhangi bir tahrifat yapılmamış ve bu çalışma herhangi başka bir akademik yayın ortamına değerlendirme için gönderilmemiştir. Ayrıca bu çalışma da kullanılan veriler akademik etik kurul izni gerektirmeyen ve herkes tarafindan ulaşılabilen verilerden oluşmaktadır.

\section{Kaynakça}

Alvarez, S. A. ve Busenitz, L. W. (2001). The entrepreneurship of resource-based theory.Journal of Management, 27(6), $755-775$.

Arrkan, S. (2002). Girsisimcilik temel kavramlar ve baəz güncel konular. Ankara: Siyasal Kitabevi.

Arıkan, C. (2016). Kadın girişimcilikte başarı ve başarısızlı̆̆ etkileyen faktörler: bursa örneği. Yönetim ve Ekonomi Arasttrmalar Dergisi, 14(3), 138-156.

Aytaç, Ö. ve İlhan, S. (2007). Girişimcilik ve girişimcikültür: Sosyolojik bir perspektif.Selçuk Üniversitesi Sosyal Bilimler Enstituisï Dergisi, 18, 101-120.

Ball, A. (2017). Girişimcilik ve girişimci tipolojileri.Süleyman Demirel Üniversitesi Sosyal Bilimler Enstituisü Dergisi,4(29), $143-166$.

Bates, T. (2005). Analysis of young, small firms that have closed: Delineating successful from unsuccessful closures. Journal of Business Venturing, 20(3),343-358.

Baumeister, R. F., Bratslavsky, E., Finkenauer, C. ve Vohs, K. D. (2001). Bad is stronger than good. Review of General Psychology, 5(4), 323-370.

Brophy, D. J. ve Shulman, J. M. (1992). A finance perspective on entrepreneurship research. Entrepreneurship Theory and Practice, 16(3), 61-72.

Bledow, R., Carette, B., Kühnel, J. ve Bister, D. (2017). Learning from others' failures: The effectiveness of failure stories for managerial learning. Academy of Management Learning \& Education, 16(1), 39-53.

Bozkurt, Ö. Ç., Kalkan, A., Koyuncu, O. ve Alparslan, A. M. (2012). Türkiye'de girişimciliğin gelişimi: Girişimciler üzerinde nitel bir araştırma. Süleyman Demirel Üniversitesi Sosyal Bilimler Enstitiisï Dergisi, 15, 229-247.

Bozkurt, Ö., Ercan, A. ve Yurt, İ. (2018). Bireysel değerler ile girişimcilik eğilimi arasındaki ilişkinin değerlendirilmesi: Düzce Üniversitesi örneği. Girrșimcilik ve Kalkinma Dergisi, 13(1), 43-55.

Bruton, G. D., Ahlstrom, D. ve Obloj, K. (2008). Entrepreneurship in emerging economies: Where are we today and where should the research go in the future. Entrepreneurship: Theory and Practice, 32(1), 1-14.

Byrne, O. ve Shepherd, D. A. (2015). Different strokes for different folks: Entrepreneurial narratives of emotion, cognition, and making sense of business failure. EntrepreneurshipTheory and Practice, 39(2), 375-405.

Cannon, M. D. ve Edmonson, A. C. (2005). Failing to learn and learning to fail (intelligently): How great organizations put failure to work to innovate and improve. Long Range Planning, 38, 299-319.

Cardon, M. S., Stevens, C. E. ve Potter, D. R. (2011). Misfortunes or mistakes? Cultural sense making of entrepreneurial failure. Journal of Business Venturing, 26, 79-92.

Carree, M. ve Thurik, R. (2010). The impact of entrepreneurship on economic growth. In Z. J. Acs and D. B. Audretsch (Eds.). Handbook of entrepreneurship research. New York: Springer.

Coad, A. (2014). Death is not a success: Reflections on business exit. International Small Business Journal, 32(7), 721 732.

Cope, J. (2011) Entrepreneurial learning from failure: An interpretative phenomenological analysis. Journal of Business Venturing, 26(6), 604-623.

De Bettignies, J. E. ve Brander, J. A. (2007). Financing entrepreneurship: Bank finance versus venture capital. Journal of Business Venturing, 22(6), 808-832.

Delacroix, J. ve Carroll, J. (1983). Organizational foundings: An ecological study of the newspaper industries of Argentina and Ireland. Administrative Science Quarterly, 28, 274-291

Derindağ, Ö. F. (2018). Girişimcilik başarısını etkileyen unsurlar: kişilik özellikleri bağlamında bir analiz. Uluslararası Yönetim Ë̈itim ve Ekonomik Perspektifler Dergisi, 6(3), 1-12.

DeTienne, D. R. (2010). Entrepreneurial exit as a critical component of the entrepreneurial process: Theoretical development. Journal of Business Venturing,25(2), 203-215.

DeTienne, D. R., McKelvie, A. ve Chandler, G. N. (2014) Making sense of entrepreneurial exitstrategies: A typology and test. Journal of Business Venturing,30(2), 255-272.

Edelman, L. F., Manolova, T., Shirokova, G. ve Tsukanova, T. (2016). The impact of family support on young entrepreneurs' start-up activities. Journal of Business Venturing, 31(4), 428-448.

Eser, G. ve Yıldız, M. (2015). Türkiye'de girişimcilik araştırmalarının odağı nedir?-Yazın $\quad$ üzerine bir inceleme-. Öneri Dergisi, 11(43), 91-117. 
Frankish, J. S., Roberts R. G., Coad, A. vd. (2013) Do entrepreneurs really learn? Or do they just tell us that they do? Industrial and Corporate Change, 22(1), 73-106.

Gaskill, L., Van Auken, H. ve Manning, R. (1993) A factor analytic study of the perceived causes of small business failure. Journal of Small Business Management, 31(4), 18-31.

Gilbert, B. A., Audretsch, D. B. ve McDougall, P. P. (2004). The emergence of entrepreneurship policy. Small Business Economics, 22(3-4), 313-323.

Güney, S. (2004). Girişimcilik: Temel kavramlar ve baz̨ güncel konular (3. Basım). Ankara: Siyasal Kitapevi.

Headd, B. (2003). Redefining business success: Distinguishing between closure and failure. Small Business Economics, 21, 51-61.

Hoetker, G. ve Agarwal, R., (2007). Death hurts, but it isn't fatal: the post exit diffusion of knowledge created by innovative companies. Academy of Management Journal, 50, 446-467.

Hsu, D. K., Wiklund, J. ve Cotton, R. D. (2017). Success, failure, and entrepreneurial reentry: An experimental assessment of the veracity of self-efficacy and prospect theory. Entrepreneurship Theory and Practice, 41(1), 19-47.

Jenkins, A. S., Wiklund, J. ve Brundin, E. (2014). Individual responses to firm failure: Appraisals, grief, and the influence of prior failure experience. Journal of Business Venturing, 29(1), 17-33.

Jenkins, A. ve McKelvie A.(2016). What is entrepreneurial failure? implications for future research.International Small Business Journal,34(2), 176-188

Karimi, S., Biemans, H. J., Naderi Mahdei, K., Lans, T., Chizari, M. ve Mulder, M. (2017). Testing the relationship between personality characteristics, contextual factors and entrepreneurial intentions in a developing country. International Journal of Psychology, 52(3), 227-240.

Keskin, S. (2017). Kadın ve erkek girişimciler arasındaki farkl11klar. Mersin Üniversitesi Sosyal Bilimler Enstitüsü Dergisi,1(1), 64-76.

Keskin, S. (2018). Yeni girişimlerin başarısızlık nedenlerinin analizi: Ampirik bir çalışma. Abi Evran Üniversitesi İktisadi ve İdari Bilimler Fakültesi Dergisi, 2(1), 147-158.

Knight, F. (1921).Risk, uncertainty and profit. Boston, MA: Houghton Mifflin.

Knott, A. M. ve Posen, H. E. (2005). Is failure good? Strategic Management Journal, 26, 617-641.

Lee, S. H., Yamakawa, Y., Peng, M. W. ve Barney, J. B. 2011. How do bankruptcy laws affect entrepreneurship development around the world? Journal of Business Venturing, 26(5), 505-520.

Lezki, Ş. ve Cengiz, A. A. (2019). Eskişehir'de Kadın Girişimcilerin Motivasyon Faktörleri Üzerine Bir Araștırma. Uluslararası Yönetim Íktisat ve İsletme Dergisi, 15(3), 814-833.

Link, A. N. (2017). Ideation, entrepreneurship, and innovation. Small Business Economics, 48(2), 279-285.

Lumpkin, G. T., Steier, L. ve Wright, M. (2011). Strategic entrepreneurship in family business. Strategic Entrepreneurship Journal,5(4), 285-306.

Macko, A. ve Tyszka, T. (2009). Entrepreneurship and risk taking. Applied psychology, 58(3), 469-487.

Madsen, P. M. ve Desai, V. (2010). Failing to learn? The effects of failure and success on organizational learning in the global orbital launch vehicle industry. Academy of management journal, 53(3), 451-476.

Martin, B. C., McNally, J. J. ve Kay, M. J. (2013). Examining the formation of human capital in entrepreneurship: A meta-analysis of entrepreneurship education outcomes. Journal of Business Venturing, 28(2), 211-224.

McGrath, R. G. (1999). Falling forward: Real options reasoning and entrepreneurial failure. Academy of Management Review,24(1), 13-30.

Müftüoğlu, T.M. (2003). Girişimciler için işletme yönetimi. Gazi Kitabevi, Ankara.

Pehlivanoğlu, F. ve Kayan, K. (2019). Türkiye'de girişimcilik: Mevcut durum analizi ve çözüm önerileri. Kırklareli Üniversitesi İktisadi ve İdari Bilimler Fakültesi Dergisi, 8(1), 58-78.

Pathak, S., Xavier-Oliveira, E. ve Laplume, A. O. (2013). Influence of intellectual property, foreign investment, and technological adoption on technology entrepreneurship. Journal of Business Research, 66(10), 2090-2101.

Politis, D. ve Gabrielsson, J. (2009). Entrepreneurs' attitudes towards failure. International Journal of Entrepreneurial Behaviour \& Research, 15(4), 364-383.

Rerup, C. (2006). Success, failure and the gray zone: How organizations learn or do not learn from ambiguous experience. Paper presented at the Academy of Management Best Paper Proceedings.

Sarasvathy, S. D. (2004). The questions we ask and the questions we care about: Reformulating some problems in entrepreneurship research. Journal of Business Venturing, 19(5), 707-717.

Sarasvathy, S. D., Menon, A.ve Kuechle, G. (2013). Failing firms and successful entrepreneurs: Serial entrepreneurship as a temporal portfolio. Small Business Economics, 40(2), 417-434.

Shepherd, D. A. (2003). Learning from business failure: Propositions about the grief recovery process for the selfemployed. Academy of Management Review, 282, 318-329.

Shepherd, D. A. ve Wiklund, J. (2006). Successes and failures at research on business failure and learning from it. Foundations and Trends in Entrepreneurship 2(5). Available at: http://papers.ssrn.com/sol3/papers.cfm?abstract_id=1629315

Shepherd, D. A. (2009). Grief recovery from the loss of a family business: A multi- and meso-level theory. Journal of Business Venturing, 24(1), 81-97.

Shepherd, D. A. ve Haynie, J. M. (2011). Venture failure, stigma, and impression management: A self-verification, self-determination view. Strategic Entrepreneurship Journal, 5(2), 178-197.

Schumpeter, J. (1934). The theory of economic development. Cambridge, MA: Harvard University Press. 
Simmons, S., Wiklund, J.ve Levie, J. (2013). Stigma and business failure: Implications for entrepreneurs'career choices. Small Business Economics, 42(3), 1-21.

Singh, S., Corner, P.ve Pavlovich, K. (2007). Coping with entrepreneurial failure. Journal of Management and Organization, 13(4), 331-344.

Singh, S., Corner, P. D.ve Pavlovich, K (2015). Failed, not finished: A narrative approach to understanding venture failure stigmatization. Journal of Business Venturing, 30(1), 150-166.

Soysal, A.(2010).Türkiye de kadın girişimciler engeller ve firsatlar bağlamında bir değerlendirme. Ankara Üniversitesi Siyasal Bilgiler Fakültesi Dergisi, 65-1

Üçbaşaran, D., Westhead, P., Wright, M.ve Flores, M. (2010). The nature of entrepreneurial experience, business failure and comparative optimism. Journal of Business Venturing, 25(6), 541-555.

Üçbaşaran, D., Shepherd, D. A. ve Lockett, A. (2013). Life after business failure: The process and consequences of business failure for entrepreneurs. Journal of Management, 39(1), 163-202.

von Weizsäcker, E. U. (2014). We have to embed egoism. In Sustainable Entrepreneurship. Springer, Berlin, Heidelberg. pp. 283-285

Watson, J. ve Everett, J. E. (1996). Do small businesses have high failure rates? Evidence from Australian retailers. Journal of Small Business Management, 34(4), 45-62.

Welter, F. ve Smallbone, D. (2006). Exploring the role of trust in entrepreneurial activity. Entrepreneurship Theory and Practice, 30(4), 465-475.

Welter, F. ve Smallbone, D. (2011). Institutional perspectives on entrepreneurial behavior in challenging environments. Journal of Small Business Management, 49(1), 107-125.

Welter, F. (2012). All you need is trust? A critical review of the trust and entrepreneurship literature. International Small Business Journal,30(3), 193-212.

Wennberg, K., Wiklund, J. ve De'Tienne, D. R. (2010) Reconceptualizing entrepreneurial exit: Divergent exit routes and their drivers. Journal of Business Venturing, 25(4), 367-375

Wiklund, J., Baker, T. ve Shepherd, D. (2010). The age effect of financial indicators as buffers against the liabilities of new ness. Journal of Business Venturing, 25, 423-437

Zacharakis, A., Meyer, G. ve DeCastro, J. (1999). Differing perceptions of new venture failure: A matched exploratory study of venture capitalists and entrepreneurs. Journal of Small Business Management, 37(3), 1-14.

www.tobb.gov.tr

\section{EXTENDED ABSTRACT}

Entrepreneurship is a very important concept for both individuals and society. It is observed that the success factor is emphasized in popular and academic studies related to entrepreneurship. However, statistics show that new initiatives in our country have resulted in serious failure. Therefore, success as well as failure is one of the important concepts in entrepreneurship.

The concept of failure in entrepreneurship is often referred to as the ending of enterprises, bankruptcy and the failure of business. From a historical perspective, the failure of the enterprise and the failure of the entrepreneur were considered to be synonymous. In this study, videos of entrepreneurs who express themselves that they have failed will be subjected to content analysis and the themes of failure will be revealed. In this way, attention will be drawn to neglected aspects of entrepreneurship and failure factors using reverse logic.

While failure of entrepreneurs means the end of existing enterprise, there are many examples where the entrepreneur succeeds in following initiatives. Where there is uncertainty, it is normal for failure to be as much as success. It is not necessary to think of the entrepreneurship process, where uncertainties prevail, only as success oriented. It can be a tutorial when attempts are successful or fail. Although, success stories may seem more instructive as they are brought to the fore, lessons given with failure will be more permanent. However, many psychological, social and economic effects are mentioned along with the failure. In this study, 15 video content analysis uploaded by entrepreneurs who have experience of entrepreneurship failure and who provide information about it were subjected to analysis. The selected videos consist of randomly selected videos sampling as a result of the search on the internet with the keywords "unsuccessful entrepreneurship" and "unsuccessful entrepreneurs". The videos were watched carefully, the reasons for failure in entrepreneurship were scanned and notes were taken about it. As a result, findings have been reached in light of the themes that come to the fore regarding the failure in entrepreneurship. Since the title of the analyzed videos has a negative emphasis such as failure, the rate of success stories can be expected to be less. However, it is essential to accept videos that will prevent entrepreneurs and entrepreneur candidates from making mistakes and facilitate their success as a free consultancy service. Studies conducted using qualitative methods are expected to contain more depth. The videos of unsuccessful entrepreneurs used in this sense talk about different factors that were not mentioned before and help fill the shortcomings in the literature in this sense. Findings resulting from the 
detailed analysis of the data in the videos are Environment/Family Support, Employee/Employment, Financing, Conflict between Partners, Production/Technological/Intellectual Adaptation, EgoCompetitor Underestimation - Over Confidence in Product, Market/Laws, Environment, Competitor Analysis (PEST) is presented under the headings.

As seen from the video content, even if our entrepreneurs accept cultural failure, it is not preferred to take lessons from failures and to use this information in future initiatives as required by social norms. The most important proof of this is that while videos prepared on success stories attract more attention, videos with a failure story have very low watch rates. Many viewers find videos to be inspiring, being aware of learning from failures. For example, the comment "my only success was accepting my failure but it was late" emphasizes the cultural difficulty of taking lessons from failure in our country. The comments generally describe the stories of failure as an excellent learning process. Entrepreneurs in the videos appreciate the value of their failures and think that they have received very expensive training. They said that failure will turn into success. Similarly, although there are many biographies and auto biographies written on entrepreneurial success, there are very few studies on unsuccessful entrepreneurs. Many successful entrepreneurs in our country are likely to have unsuccessful experiences before they succeed, but these are not expressed both academically and popularly. For these reasons, in order to develop entrepreneurship in practice and academic level in our country, it is necessary to investigate the causes of failure of entrepreneurs, which have been neglected, based on entrepreneurial experiences and develop realistic suggestions based on these examples. Both entrepreneur candidates and existing entrepreneurs will be more successful by accessing resources from which they can learn from mistakes. The experiences of entrepreneurs who can accept that they are unsuccessful and who question themselves should be seen as a valuable source of information.

As a result of this study, it is seen that the failure factors of entrepreneurs complement the factors necessary for success in entrepreneurship. Stories of failure can contribute to learning both in practice and at the academic level. 